\title{
Tubulointerstitial Nephritis Associated with Enteritis and Sacroiliitis
}

\author{
Shu Ushimaru ${ }^{1}$, Daisuke Ichikawa ${ }^{1}$, Masahiko Yazawa ${ }^{1}$, Tomo Suzuki ${ }^{1}$, Eri Okada ${ }^{2}$, \\ Junki Koike $^{3}$ and Yugo Shibagaki ${ }^{1}$
}

\begin{abstract}
:
The association between sacroiliitis and tubulointerstitial nephritis has not been reported. A 28-year-old man with a history of clinically diagnosed ulcerative colitis (4 years earlier) and sacroiliitis (6 months earlier) developed renal dysfunction 9 months ago, which progressed thereafter. We diagnosed him with tubulointerstitial nephritis by a renal biopsy, for which we started steroid therapy. Subsequently, his renal dysfunction, sacroiliitis, and enteritis partially improved. A pathological analysis of the kidney and intestine revealed lymphocyte infiltration and non-caseating granuloma in both organs. The similarities in the pathological findings and treatment response suggested a pathogenetic association between tubulointerstitial nephritis, enteritis, and sacroiliitis.
\end{abstract}

Key words: tubulointerstitial nephritis, sacroilitis, enteritis, granuloma

(Intern Med 58: 79-84, 2019)

(DOI: 10.2169/internalmedicine.1255-18)

\section{Introduction}

Tubulointerstitial nephritis is a disease characterized by renal dysfunction and inflammatory infiltration in the kidney interstitium. The causes of tubulointerstitial nephritis vary; however, many cases have undetermined etiologies. It is important to identify cases of tubulointerstitial nephritis with the potential for renal recovery as some patients with tubulointerstitial nephritis show at least partial improvement with early medical treatment $(1,2)$. We encountered a case of tubulointerstitial nephritis associated with the systemic chronic inflammatory diseases of ulcerative colitis and sacroiliitis. Although there have been reports of cases of tubulointerstitial nephritis associated with enteritis (3), tubulointerstitial nephritis associated with sacroiliitis has yet to be reported.

We herein report a rare case of steroid-responsive tubulointerstitial nephritis with a possible association with enteritis and sacroiliitis.

\section{Case Report}

A 28-year old man with a history of enteritis (clinically diagnosed as ulcerative colitis) and sacroiliitis was referred to our nephrology clinic with progressive kidney dysfunction. Four years ago, he had had an episode of loose stool that progressed to watery diarrhea; this led to the diagnosis of mild ulcerative colitis by colonoscopy, which improved without medication. He had also reported having mild lumbar pain. At that time, his serum creatinine level was normal $(0.89 \mathrm{mg} / \mathrm{dL})$. Nine months earlier, during a routine medical checkup, he was found to have a serum creatinine level of $2.1 \mathrm{mg} / \mathrm{dL}$, for which he did not consult a physician. Six months earlier, he had experienced right buttock pain, which was diagnosed as sacroiliitis and was resolved symptomatically with non-steroidal anti-inflammatory drug (NSAID) administration. Three months earlier, he visited a hospital repeatedly for numbness of the right femoral flexor, and his serum creatinine level had increased to $2.75 \mathrm{mg} / \mathrm{dL}$, for which he was referred to our clinic.

\footnotetext{
${ }^{1}$ Division of Nephrology and Hypertension, Department of Internal Medicine, St. Marianna University School of Medicine, Japan, ${ }^{2}$ Department of Nephrology, National Hospital Organization Chiba-East-Hospital, Japan and ${ }^{3}$ Department of Pathology, Kawasaki Municipal Tama Hospital, Japan

Received: March 25, 2018; Accepted: June 5, 2018; Advance Publication by J-STAGE: August 24, 2018

Correspondence to Dr. Daisuke Ichikawa, ichikawa6008@gmail.com
} 
Table. Laboratory Data at the Time of Admission.

\begin{tabular}{|c|c|c|c|}
\hline Blood Count & & Urinalysis findings & \\
\hline White blood cells & $10,800 / \mu \mathrm{L}$ & Gravity & 1.013 \\
\hline Segment & & $\mathrm{pH}$ & 5.5 \\
\hline Neutrophil & $64 \%$ & Protein & $221.5 \mathrm{mg} /$ day \\
\hline Lymphocyte & $20 \%$ & Albumin & $33 \mathrm{mg} /$ day \\
\hline Monocyte & $6 \%$ & Glucose & $(-)$ \\
\hline Eosinophil & $9 \%$ & Occult blood & $( \pm)$ \\
\hline Basophil & $0 \%$ & Red blood cells & $5-9 / \mathrm{HPF}$ \\
\hline Red blood cells & $409 \times 10^{4} / \mu \mathrm{L}$ & White blood cells & 20-29 /HPF \\
\hline Hemoglobin & $11.6 \mathrm{~g} / \mathrm{dL}$ & Epithelial cast & $(+)$ \\
\hline Hematocrit & $35.3 \%$ & Leukocyte cast & $(+)$ \\
\hline Platelet & $476 \times 10^{3} / \mu \mathrm{L}$ & $\alpha 1$-microglobulin & $44.5 \mathrm{mg} / \mathrm{L}$ \\
\hline Blood chemistry & & $\beta 2$-microglobulin & $2,426 \mu \mathrm{g} / \mathrm{L}$ \\
\hline Total protein & $9.3 \mathrm{~g} / \mathrm{dL}$ & NAG & $10.8 \mathrm{U} / \mathrm{L}$ \\
\hline Albumin & $4.5 \mathrm{~g} / \mathrm{dL}$ & Immunologic findings & \\
\hline Total bilirubin & $0.4 \mathrm{mg} / \mathrm{dL}$ & Immunoglobulin A & $522 \mathrm{mg} / \mathrm{dL}$ \\
\hline AST & $16 \mathrm{U} / \mathrm{L}$ & Immunoglobulin $\mathrm{G}$ & $2,828 \mathrm{mg} / \mathrm{dL}$ \\
\hline ALT & $8 \mathrm{U} / \mathrm{L}$ & Immunoglobulin $\mathrm{M}$ & $256 \mathrm{mg} / \mathrm{dL}$ \\
\hline ALP & $185 \mathrm{U} / \mathrm{L}$ & ASO & $719 \mathrm{IU} / \mathrm{mL}$ \\
\hline LDH & $124 \mathrm{U} / \mathrm{L}$ & $\mathrm{M}$ protein & $(-)$ \\
\hline Creatinine & $2.92 \mathrm{mg} / \mathrm{dL}$ & Anti-nuclear antibody & $(-)$ \\
\hline Urea nitrogen & $27 \mathrm{mg} / \mathrm{dL}$ & c-ANCA & $(-)$ \\
\hline Sodium & $136 \mathrm{mEq} / \mathrm{L}$ & p-ANCA & $(-)$ \\
\hline Potassium & $4 \mathrm{mEq} / \mathrm{L}$ & Cryoglobulin & $(-)$ \\
\hline Chloride & $103 \mathrm{mEq} / \mathrm{L}$ & Anti-cardiolipin antibody & $(-)$ \\
\hline Calcium & $9.4 \mathrm{mg} / \mathrm{dL}$ & Anti-SS-A antibody & $(-)$ \\
\hline Phosphorus & $3 \mathrm{mg} / \mathrm{dL}$ & Anti-SS-B antibody & $(-)$ \\
\hline \multirow[t]{4}{*}{ C-reactive protein } & $2.13 \mathrm{mg} / \mathrm{dL}$ & Complement 3 & $126 \mathrm{mg} / \mathrm{dL}$ \\
\hline & & Complement 4 & $32 \mathrm{mg} / \mathrm{dL}$ \\
\hline & & $\mathrm{ACE}$ & $17.8 \mathrm{U} / \mathrm{L}$ \\
\hline & & KL-6 & $555 \mathrm{U} / \mathrm{mL}$ \\
\hline
\end{tabular}

NAG: N-acetyl- $\beta$-D-glucosaminidase, ASO: antistreptolysin O, c-ANCA: cytoplasmic-anti-neutrophil cytoplasmic antibody, p-ANCA: perinuclear-anti-neutrophil cytoplasmic antibody, ACE: angiotensin-converting enzyme. KL-6: Krebs von den Lungen-6

His medical history included systemic chronic inflammatory diseases (enteritis and sacroiliitis) with chronic leukocytosis [white blood cell (WBC) count 10,000-13,000/ $\mathrm{LL}$; neutrophil count $64 \%$, eosinophil count $9 \%$ ]. His family medical history included rheumatoid arthritis (paternal grandmother) and Crohn's disease (younger brother) but no renal failure or urinary abnormalities. His current medications were clarithromycin (dose unknown) and NSAID, administered as required. He was a non-smoker and non-drinker and had no allergies.

A physical examination showed a single painless canker sore and mildly enhanced intestinal peristalsis without pain and distension; in addition, the patient reported an uncomfortable feeling (no pain or tenderness) in the sacroiliac joint and spine; otherwise, findings of the muscles, bones, joints, and skin were unremarkable. Table presents the laboratory data obtained from the patient on admission. Urinalyses revealed hematuria, with 5-9 red blood cells/high-power field (HPF), 20-29 WBCs/HPF (no eosinophils in the urine), an epithelial cast, a leukocyte cast, and poikilocytosis, although no abnormality on urinalysis had been reported previously.
The urine protein excretion was $0.2 \mathrm{~g} /$ day (albuminuria 0.03 $\mathrm{g} /$ day), and the urinary $\mathrm{N}$-acetyl- $\beta$-D-glucosaminidase (NAG), urinary alpha-1 microglobulin $(\alpha 1-\mathrm{MG})$, and urinary beta-2 microglobulin ( $\beta 2-\mathrm{MG}$ ) levels were elevated to 10.8 $\mathrm{U} / \mathrm{L}$ (reference range, $0.8-11.0 \mathrm{U} / \mathrm{L}$ ), $44.5 \mathrm{mg} / \mathrm{L}$ (reference range, $0-8.3 \mathrm{mg} / \mathrm{L}$ ), and $2,426 \mu \mathrm{g} / \mathrm{L}$ (reference range, $0-200$ $\mu \mathrm{g} / \mathrm{L}$ ), respectively. On a complete blood cell count analysis, the WBC and eosinophil counts were found to be elevated to $10,800 / \mu \mathrm{L}$ and $9 \%$ eosinophilia, respectively. An ultrasonogram of both kidneys showed that they measured about $10.0 \mathrm{~cm}$, without hydronephrosis, and had an irregular shape and echogenic renal parenchyma. Plain chest-abdominal computed tomography showed that both kidneys were mildly atrophic, without hydronephrosis.

Suspecting that the patient had systemic chronic inflammatory diseases, we performed more tests to assess his kidney dysfunction. A blood test showed an elevated sedimentation rate, polyclonal gammopathy (IgA level $522 \mathrm{mg} / \mathrm{dL}$, IgG level 2,828 $\mathrm{mg} / \mathrm{dL}$, and $\mathrm{IgM}$ level $256 \mathrm{mg} / \mathrm{dL}$ ) with no $\mathrm{M}$ protein detected on immunoelectrophoresis, and an elevated antistreptolysin O (ASO) level $(719 \mathrm{IU} / \mathrm{mL})$. The pa- 
A

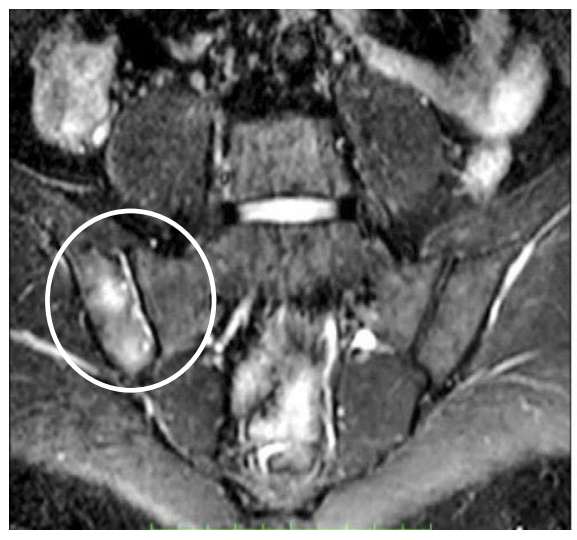

B

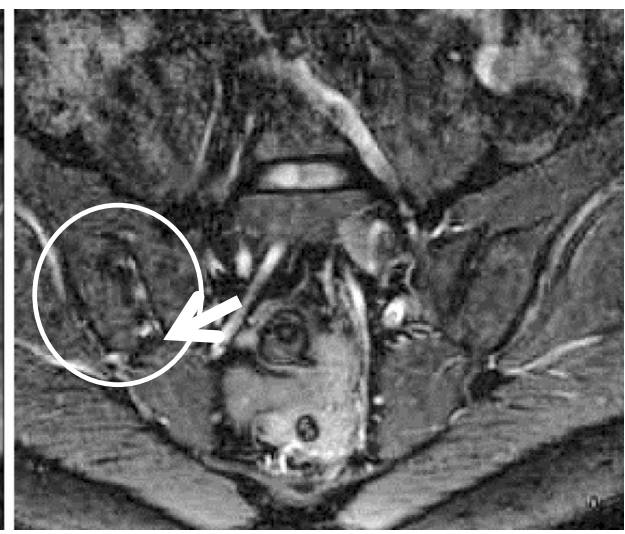

Figure 1. Magnetic resonance imaging (fat-suppressed T1-weighted imaging) demonstrating the location of the patient's pain. (A) Right sacroiliac joint showing a high-intensity signal before steroid therapy. (B) The unilateral high-intensity signal disappeared after steroid therapy (arrow).

tient was negative for anti-nuclear antibody (ANA), perinuclear-anti-neutrophil cytoplasmic antibody (p-ANCA), cytoplasmic-anti-neutrophil cytoplasmic antibody (c-ANCA), cryoglobulin, anti-cardiolipin antibody, and anti-SS-A/antiSS-B antibodies, and the serum levels of complement, angiotensin-converting enzyme, and Krebs von den Lungen (KL)-6 as well as the thyroid gland function were all within normal limits. The results of an ophthalmologic examination were normal as well. A fat biopsy was negative for amyloids. Thus, the aforementioned blood and imaging test results indicated that although the patient had chronic inflammation, paraproteinemia and ANA- or ANCA-associated vasculitis or collagen diseases were unlikely to be the cause.

The patient had enteritis, clinically diagnosed as ulcerative colitis, with the disappearance of the visible vascular pattern of the intestine macroscopically and lymphocyte infiltration and granuloma pathologically. However, our gastrointestinal specialist could not diagnose this lesion as inflammatory bowel disease (IBD), although there were potential signs of remnant IBD. As a result, we suspected that he had autoimmune enteritis of an unknown etiology.

Magnetic resonance imaging (fat-suppressed T1-weighted imaging) showed a high-density area in the right sacroiliac joint, confirming the diagnosis of sacroiliitis (Fig. 1A); however, as the symptom of sacroiliitis was only mild lumbar pain, we did not consider treating the sacroiliitis. He showed human leukocyte antigen (HLA)-B27 negativity and HLAB51 positivity but had none of the main symptoms of Behçet's disease.

Figure 2 shows the patient's clinical course. His kidney dysfunction progressed over several years. The causes of kidney dysfunction were suspected to be tubulointerstitial nephritis due to non-albumin-dominant proteinuria, elevated urinary tubular biomarker levels ( $\alpha 1-\mathrm{MG}, \beta 2-\mathrm{MG}$, and NAG), and sterile pyuria. We suspected that renal failure, sacroiliitis, and enteritis were associated with each other because of the concomitant course of the three pathologies.

To make a definitive diagnosis, we performed a percuta- neous renal biopsy on day 34 from the initial presentation. Light microscopy showed diffuse interstitial cell infiltration and mild-to-moderate fibrosis (Fig. 3A). Of the 24 glomeruli obtained, 2 showed global sclerosis, and the others were almost intact. The HPF showed tubulitis and interstitial cellular invasion, with the infiltrating cells including many lymphocytes and plasma cells as well as few eosinophils but no neutrophils. The granuloma consisted of the interstitium of the renal tissue (cortex) (Fig. 3B). The results of an immunohistochemical analysis for $\operatorname{IgA}, \operatorname{IgG}, \operatorname{IgM}, \mathrm{C} 1 \mathrm{q}, \mathrm{C} 3 \mathrm{c}, \kappa$, and $\lambda$ were all negative. Electron microscopy showed interstitial cellular invasion, although the glomeruli were intact. We confirmed a diagnosis of tubulointerstitial nephritis.

We expected his renal disorder to improve with treatment because his renal tissue had an acute lesion and the glomerular formation was intact. We started intravenous steroid pulse therapy for 3 days, followed by oral prednisolone, starting at a dose of $30 \mathrm{mg} /$ day with tapering. We reduced the prednisolone dose by $5 \mathrm{mg}$ every month until it was 10 $\mathrm{mg} /$ day and then reduced the dose by $2.5 \mathrm{mg}$ every month until it was $5 \mathrm{mg} /$ day and then by $1 \mathrm{mg}$ every month thereafter. The serum creatinine level decreased from $3.15 \mathrm{mg} / \mathrm{dL}$ to $2.32 \mathrm{mg} / \mathrm{dL}$, but no further improvement was observed. The C-reactive protein (CRP) level decreased from $2.22 \mathrm{mg} /$ $\mathrm{dL}$ to $<0.03 \mathrm{mg} / \mathrm{dL}$. The urinary tubular biomarker levels decreased as well [NAG from $10.8 \mathrm{U} / \mathrm{L}$ to $0.9 \mathrm{U} / \mathrm{L}$ (reference range, $0.8-11.0 \mathrm{U} / \mathrm{L}), \alpha 1-\mathrm{MG}$ from $44.5 \mathrm{mg} / \mathrm{L}$ to 5.7 $\mathrm{mg} / \mathrm{L}$ (reference range, 0-8.3 mg/L), $\beta 2-\mathrm{MG}$ from 2,426 $\mu \mathrm{g} /$ $\mathrm{L}$ to $647 \mu \mathrm{g} / \mathrm{L}$ (reference range, $0-200 \mu \mathrm{g} / \mathrm{L}$ )]. The symptoms of sacroiliitis (buttock pain) and enteritis (diarrhea) also improved simultaneously; indeed, 4 months after starting steroid therapy (prednisolone $10 \mathrm{mg}$ ), his buttock pain and diarrhea had almost disappeared. Magnetic resonance imaging (fat-suppressed T1-weighted imaging) showed the disappearance of the unilateral high-intensity area after steroid therapy (Fig. 1B). 


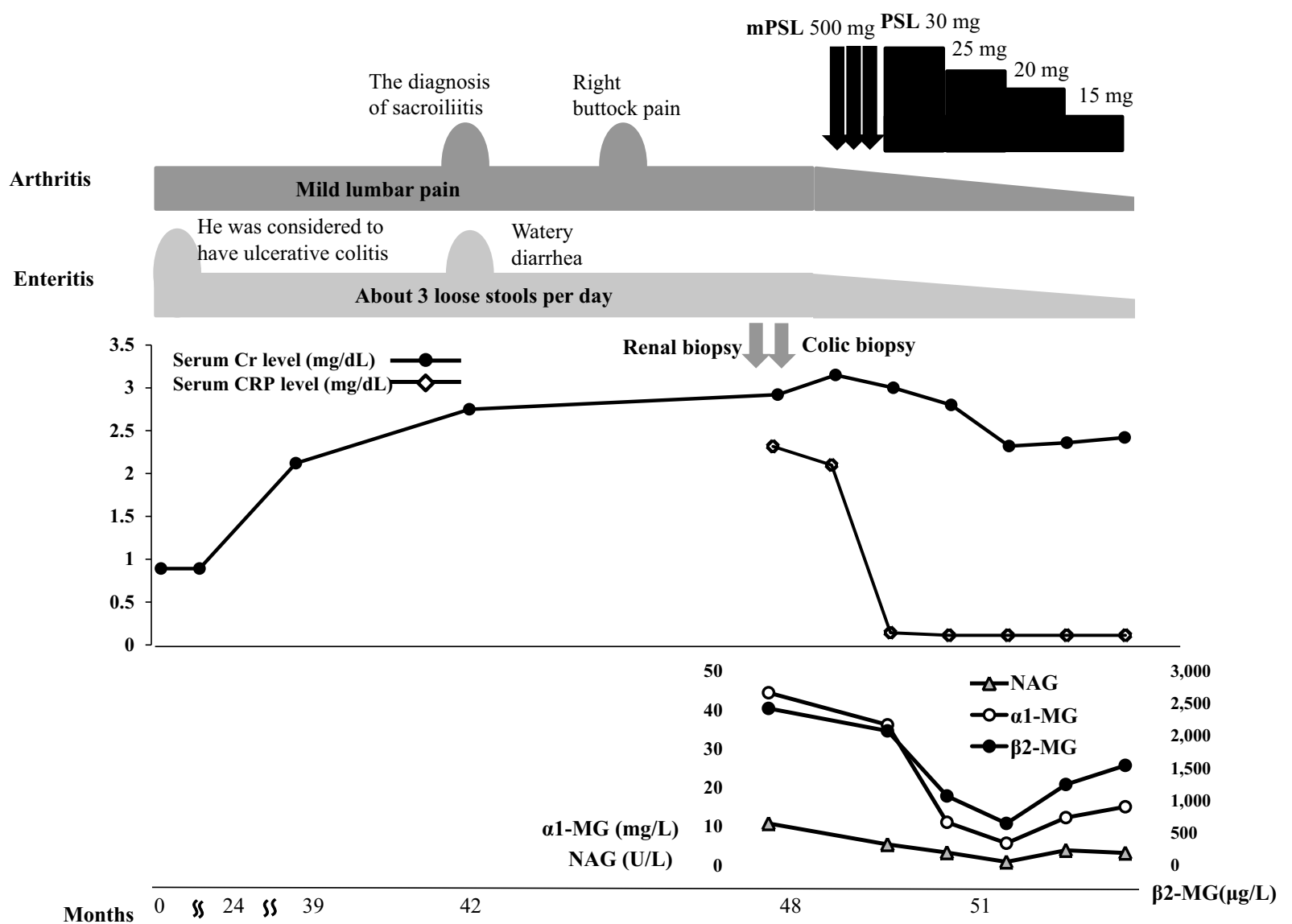

Figure 2. Patient's clinical course. Renal failure had been progressing for several years. The symptoms of both arthritis and enteritis had been maintained for four years. We considered that the renal failure, arthritis, and enteritis were associated with each other. The serum creatinine level, CRP level, and urinary tubular biomarker level were improved by steroid therapy. The symptoms of arthritis and enteritis were also improved simultaneously. Cr: creatinine, CRP: C-reactive protein, mPSL: methylprednisolone, PSL: prednisolone, NAG: N-acetyl- $\beta$-D-glucosaminidase, $\alpha 1-M G$ : alpha-1 microglobulin, $\beta 2$-MG: beta-2 microglobulin

A B

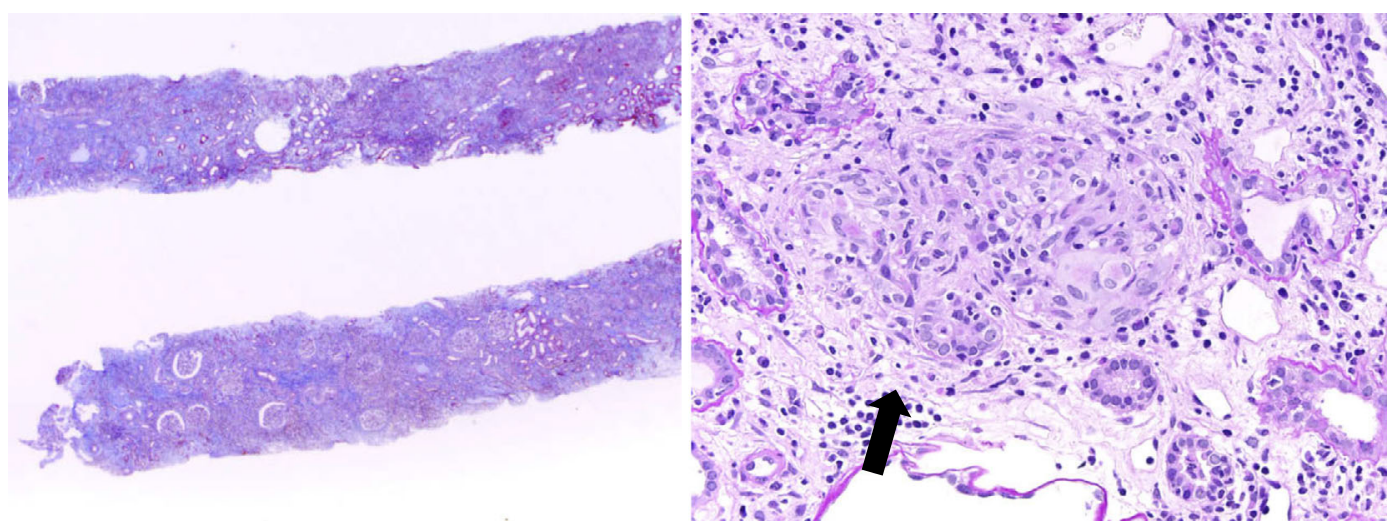

Figure 3. Histological findings of the kidney. (A) This field shows the overall infiltration of lymphocytes, plasma cells, and eosinophils in the interstitium, along with moderate tubular atrophy and interstitial fibrosis (Masson trichrome staining, $\times 20$ ). (B) Granuloma in the interstitium of the cortex (arrow) (periodic acid-Schiff staining, $\times 200)$. 


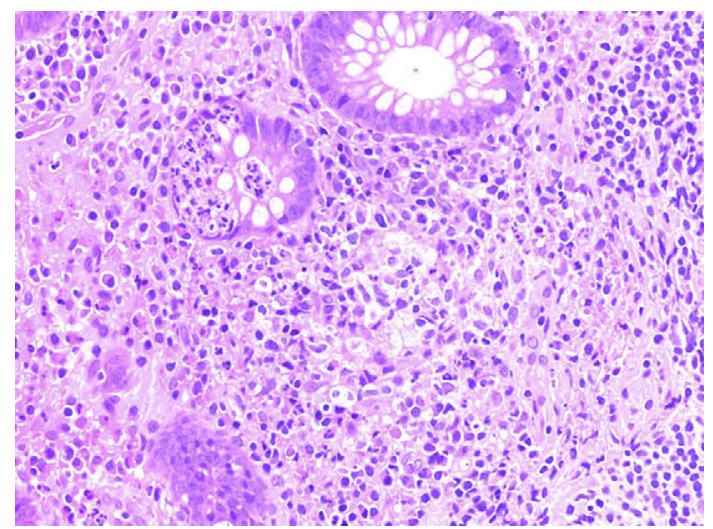

Figure 4. Histological findings of the intestine four days after the renal biopsy. Lymphocytes, plasma cells, and eosinophil infiltrates are shown in the interstitium; the further accumulation of histiocytes resembles a granuloma (periodic acid-Schiff staining, $\times 200$ ).

\section{Discussion}

To our knowledge, this is the first report of tubulointerstitial nephritis associated with enteritis and sacroiliitis. We considered tubulointerstitial nephritis to be associated with enteritis on the basis of the homology of the granulomatous lesion. Granulomatous interstitial nephritis is considered to have various etiologies, of which drug hypersensitivities and sarcoidosis, infection (specifically tuberculosis), vasculitis (particularly granulomatosis with polyangiitis), tubulointerstitial nephritis, uveitis syndrome, and IBD have been reported $(4,5)$.

We differentiated the causes of granulomatous tubulointerstitial nephritis in the present case. Regarding potential drug-induced manifestations, the patient had taken clarithromycin and NSAIDs but had only had a few episodes of tubulointerstitial nephritis during the past four years, suggesting that these drugs were unlikely to be the cause of his progressive tubulointerstitial nephritis. Regarding infections, there was a report of streptococcal infection aggravating tubulointerstitial nephritis (6), and the ASO titer varied (7), with the peak ASO titer reached at three to five weeks after pharyngitis. It has been reported that the ASO titer normalizes within several months; however, some patients experienced continued elevation of the ASO titer for more than a year (8). In some cases, an association between the ASO titer and sacroiliac joint disorder was reported (9). In the present case, the ASO titer was $719 \mathrm{IU} / \mathrm{mL}$, but 2 months earlier, the ASO titer had been $693 \mathrm{IU} / \mathrm{mL}$. The rapid test result for group A Streptococcus was negative. We considered the possibility of the involvement of chronic streptococcal infection, but the patient had no clinical manifestations of infection, so this was considered unlikely. However, the possibility of tubulointerstitial nephritis induced by ulcerative colitis was considered. The association between tubulointerstitial nephritis and IBD was first reported by Larchet et al. in 1988 (10). Their report of 83 renal biopsy cases of IBD included 16 cases of tubulointerstitial nephritis. Nine of these cases had current aminosalicylate exposure or exposure to aminosalicylates in the recent past, including all cases of granulomatous interstitial nephritis (11), although one case of tubulointerstitial nephritis with IBD without aminosalicylate use was also reported $(12,13)$. Marcus et al. reported a case in which tubulointerstitial nephritis appeared regardless of IBD activity (14). In some cases, kidney dysfunction has been observed in an early stage of Crohn's disease (15). We believe that tubulointerstitial nephritis became associated with enteritis in the long term in our patient. To our knowledge, a case in which sacroiliitis or spondylitis caused tubulointerstitial nephritis has never been reported, although the association of IBD with sacroiliitis is well known (16-18).

We speculated that tubulointerstitial nephritis was associated with enteritis because of the homology of the granulomatous lesion in the kidney and intestinal tissues. We performed a colonoscopy, including a biopsy, to evaluate the activity of enteritis four days after the renal biopsy. A granulomatous lesion existed in the kidney and intestine simultaneously (Fig. 3B, 4). The infiltrating cells mainly included lymphocytes and plasma cells and a few eosinophils but no neutrophils. The cell constitution in the interstitium of the kidney was nearly the same as that in the intestine. The predominant infiltration by lymphocytes and plasma cells along with the granuloma further supported the diagnosis of tubulointerstitial nephritis secondary to IBD-like enteritis rather than a drug-induced manifestation (19). In the present case, both the intestines and kidneys had a granuloma or the accumulation of histiocytes preceding granuloma formation. The existence of a granuloma between individual organs highlights a common etiology (20).

The association between tubulointerstitial nephritis and sacroiliitis has not been previously reported. However, some cases have reported associations between ankylosing spondylitis and abnormal findings on a urinalysis (hematuria, proteinuria, or urinary cast) (21). Cases of HLA-B51positive ankylosing spondylitis have also been reported in Japan (22). The association between ankylosing spondylitis and sacroiliitis is well known (23). Kang reported that MRI findings of iliac-dominant bone marrow edema, absent capsulitis, absent extracapsular fluid collection, and absent periarticular muscle edema indicate spondyloarthritis rather than infectious sacroiliitis (24). In the present case, MRI showed localized unilateral high density in the bone marrow before steroid therapy (Fig. 1A); however, the high density disappeared after treatment (Fig. 1B). Simultaneously, the serum creatinine level also improved. We made a diagnosis of sacroiliitis based on his MRI findings and considered the tubulointerstitial nephritis and sacroiliitis to be associated with each other.

Furthermore, during the patient's clinical course, steroid treatment improved the kidney function and the symptoms of diarrhea due to enteritis and back pain due to sacroiliitis. 
A reduction in steroid treatment caused the symptoms to recur and depressed the kidney function. Indeed, when his prednisolone dose was tapered to $5 \mathrm{mg}$, his back pain recurred after 3 weeks, and when the dose was tapered to 3 $\mathrm{mg}$, the serum creatinine level increased from an average value of $2.35 \mathrm{mg} / \mathrm{dL}$ to $2.60 \mathrm{mg} / \mathrm{dL}$, and the urinary NAG increased from a normal level to $12.9 \mathrm{U} / \mathrm{L}$. For this reason, we started tacrolimus and re-increased the prednisolone dose to $5 \mathrm{mg}$. Given these findings, we considered the patient's tubulointerstitial nephritis, enteritis, and sacroiliitis to be associated with each other.

We herein report a case of tubulointerstitial nephritis associated with enteritis or sacroiliitis, possibly from the same etiology. To our knowledge, this is the first reported case of sacroiliitis associated with tubulointerstitial nephritis. We suggest that a pathogenetic association of these manifestations be considered in cases of tubulointerstitial nephritis with sacroiliitis and/or enteritis.

The findings from the present case suggest that tubulointerstitial nephritis may be complicated if a patient with a combination of enterocolitis and sacroiliitis exhibits acute kidney injury. If tubulointerstitial nephritis is found on a renal biopsy, treatment with steroids will improve the acute renal injury; it may therefore be best to perform a renal biopsy proactively.

The authors state that they have no Conflict of Interest (COI).

\section{References}

1. González E, Gutiérrez E, Galeano C, et al. Early steroid treatment improves the recovery of renal function in patients with druginduced acute interstitial nephritis. Kidney Int 73: 940-946, 2008.

2. Muriithi AK, Leung N, Valeri AM, et al. Biopsy-proven acute interstitial nephritis. Am J Kidney Dis 64: 558-566, 2014.

3. Calviño J, Romero R, Pintos E, et al. Mesalazine-associated tubule-interstitial nephritis in inflammatory bowel disease. Clin Nephrol 49: 265-267, 1998.

4. Joss N, Morris S, Young B, Geddes C. Granulomatous interstitial nephritis. Clin J Am Soc Nephrol 2: 222-230, 2007.

5. Shah S, Carter-Monroe N, Atta MG. Granulomatous interstitial nephritis. Clin Kidney J 8: 516-523, 2015.

6. Dharmarajan TS, Yoo J, Russell RO, Boateng YA. Acute post streptococcal interstitial nephritis in an adult and review of the literature. Int Urol Nephrol 31: 145-148, 1999.

7. Rantz LA, Randall E, Rantz HH. Antistreptolysin O; a study of this antibody in health and in hemolytic streptococcus respiratory disease in man. Am J Med 5: 3-23, 1948.

8. Parks T, Smeesters PR, Curtis N, Steer AC. ASO titer or not? When to use streptococcal serology: a guide for clinicians. Eur J Clin Microbiol Infect Dis 34: 845-849, 2015.
9. Ben-Chetrit E, Moses AE, Agmon-Levin N, Block C, Ben-Chetrit E. Serum levels of anti-streptolysin $O$ antibodies: their role in evaluating rheumatic diseases. Int J Rheum Dis 15: 78-85, 2012.

10. Larchet M, Guillot M, Mandard JC, et al. Crohn's enteritis and chronic tubulo-interstitial nephropathy in an adolescent. Arch Fr Pediatr 45: 649-651, 1988.

11. Ambruzs JM, Walker PD, Larsen CP. The histopathologic spectrum of kidney biopsies in patients with inflammatory bowel disease. Clin J Am Soc Nephrol 9: 265-270, 2014.

12. Shahrani Muhammad HS, Peters C, Casserly LF, Dorman AM, Watts M. Relapsing tubulointerstitial nephritis in an adolescent with inflammatory bowel disease without aminosalicylate exposure. Clin Nephrol 73: 250-252, 2010.

13. Herrlinger KR, Noftz MK, Fellermann K, Schmidt K, Steinhoff J, Stange EF. Minimal renal dysfunction in inflammatory bowel disease is related to disease activity but not to 5-ASA use. Aliment Pharmacol Ther 15: 363-369, 2001.

14. Marcus SB, Brown JB, Melin-Aldana H, Strople JA. Tubulointerstitial nephritis: an extraintestinal manifestation of Crohn disease in children. J Pediatr Gastroenterol Nutr 46: 338-341, 2008.

15. Izzedine H, Simon J, Piette AM, et al. Primary chronic interstitial nephritis in Crohn's disease. Gastroenterology 123: 1436-1440, 2002.

16. Leclerc-Jacob S, Lux G, Rat AC, et al. The prevalence of inflammatory sacroiliitis assessed on magnetic resonance imaging of inflammatory bowel disease: a retrospective study performed on 186 patients. Aliment Pharmacol Ther 39: 957-962, 2014.

17. Cardile S, Romano C. Current issues in pediatric inflammatory bowel disease-associated arthropathies. World J Gastroenterol 7: 45-52, 2014.

18. Gotler J, Amitai MM, Lidar M, Aharoni D, Flusser G, Eshed I. Utilizing MR enterography for detection of sacroiliitis in patients with inflammatory bowel disease. J Magn Reson Imaging 42: 121$127,2015$.

19. Colvin RB, Traum AZ, Taheri D, Jafari M, Dolatkhah S. Granulomatous interstitial nephritis as a manifestation of Crohn disease. Arch Pathol Lab Med 138: 125-127, 2014.

20. Waters AM, Zachos M, Herzenberg AM, Harvey E, Rosenblum ND. Tubulointerstitial nephritis as an extraintestinal manifestation of Crohn's disease. Nat Clin Pract Nephrol 4: 693-697, 2008.

21. Omdal R, Husby G. Renal affection in patients with ankylosing spondylitis and psoriatic arthritis. Clin Rheumatol 6: 74-79, 1987.

22. Higashi S, Nakamura T, Tomoda K, Tsukano M, Sakaguchi M, Kuga F. A study of ten Japanese patients with seronegative spondylarthropathy: a tentative proposal. Mod Rheumatol 15: 329-335, 2005.

23. Rudwaleit M. Spondyloarthritides. Z Rheumatol 76: 889-903, 2017.

24. Kang Y, Hong SH, Kim JY, et al. Unilateral sacroiliitis: differential diagnosis between infectious sacroiliitis and spondyloarthritis based on MRI findings. Am J Roentgenol 205: 1048-1055, 2015.

The Internal Medicine is an Open Access journal distributed under the Creative Commons Attribution-NonCommercial-NoDerivatives 4.0 International License. To view the details of this license, please visit (https://creativecommons.org/licenses/ by-nc-nd/4.0/).

(C) 2019 The Japanese Society of Internal Medicine Intern Med 58: 79-84, 2019 